\title{
SPONTANEOUS DISAPPEARANCE OF NEUROBLASTOMA WITH MATURATION TO GANGLIONEUROMA
}

\author{
A. L. Eyre-Brook and T. F. Hewer, Bristol, England \\ From the Bristol Royal Hospital for Sick Children
}

Perhaps the most interesting feature of neuroblastomata is their origin from cells whose normal embryological maturation into adult sympathetic nerve cells or, in the adrenal medulla, into chromaffin cells, is said to be incomplete until about the age of puberty. This observation helps to explain the occurrence of tumours of various stages of differentiation from these cells in young children, and the rare examples in which continued maturation of the neoplastic cells has accompanied their spontaneous regression.

The occurrence of spontaneous regression of neuroblastomata has been reviewed and discussed fully by Phillips (1953), Russell and Rubinstein (1959) and Willis (1960). Unfortunately it is rare for this regression to happen, and for this reason we wish to publish details of such a case.

\section{CASE REPORT}

The patient was a girl born on June 6, 1949. At the age of three months the child was noted to have a hard swelling in the right lumbar muscles. Within a further month there was

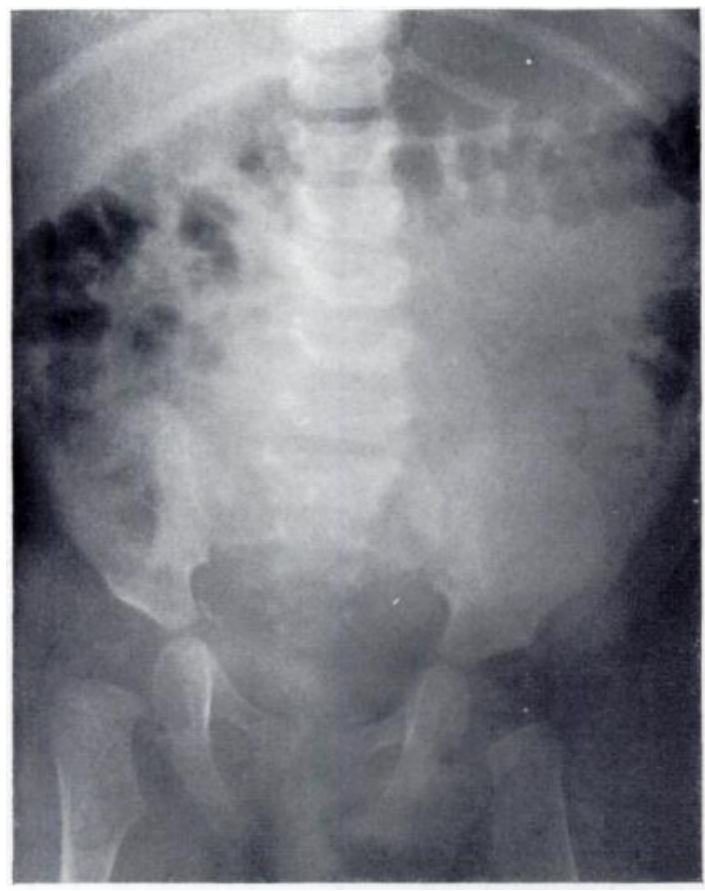

FiG. 1

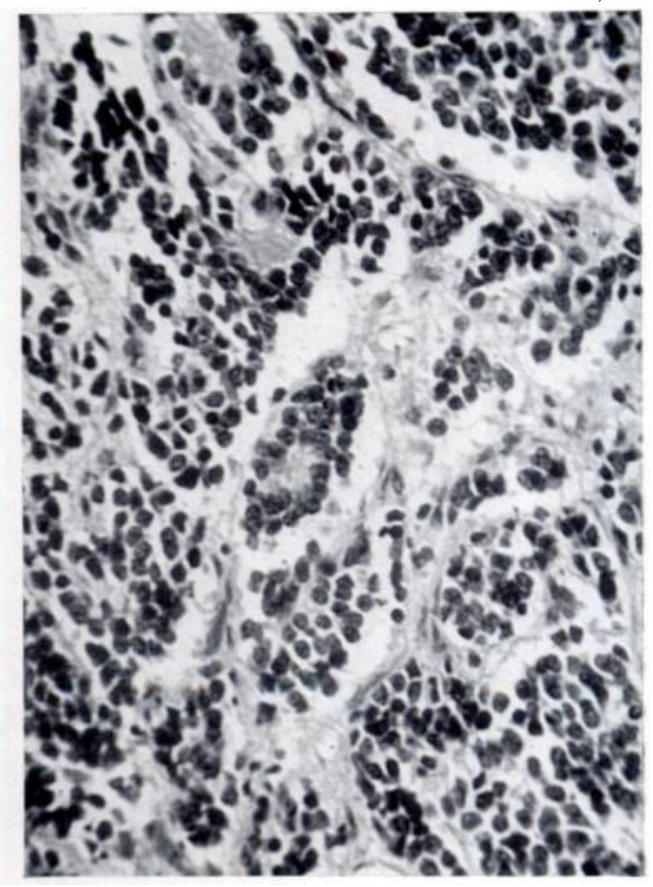

FIG. 2

Figure 1-Initial radiograph at the age of six months. Note the soft-tissue mass in the right lower abdomen and pelvis. Calcification is seen in the right side of the pelvic cavity. Figure 2-Section of biopsy specimen. There are groups of small rounded cells in a loose fibrous stroma with rosette formation. (Haematoxylin and eosin, 400.)

weakness in the left calf muscles and the lumbar swelling had grown. An abdominal swelling on the left side was readily palpated within a further four weeks, and the child was admitted to hospital at the age of five months. At that time there was a mass below and to the left of 
the umbilicus and a firm ovoid mass about an inch and a half in length in the right lumbar region. This appeared to be inseparable from the muscles and just to the side of the spine. The skin over the lump was reddened. The left leg was flexed and abducted at the hip and flexed at the knee, and there was a marked foot drop. There was no movement of the foot but slight power of extension of the knee. In the right lower limb there was no movement of the foot but normal control of the knee and hip. The urine contained pus cells and coliform bacilli.

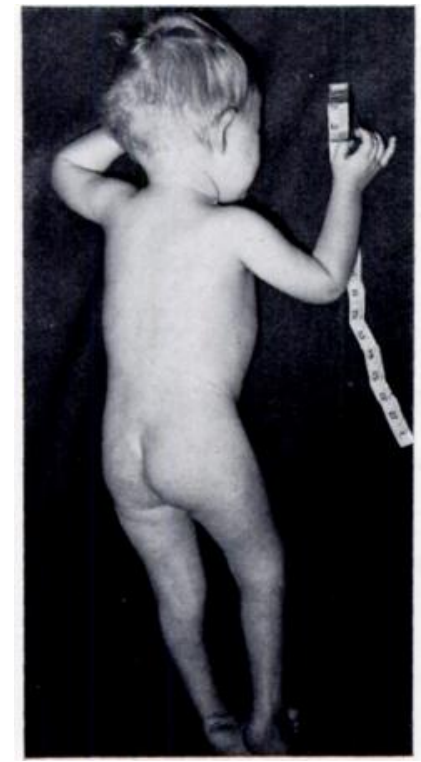

FIG. 3

FIGS. 3 AND 4

Figure 3-Aged nineteen months. The child is in good general health. Note the paralytic deformity of the feet, and the scar just above the right iliac crest. Figure 4-Aged eight years. Reasonable general health. Note the deformities of the feet.

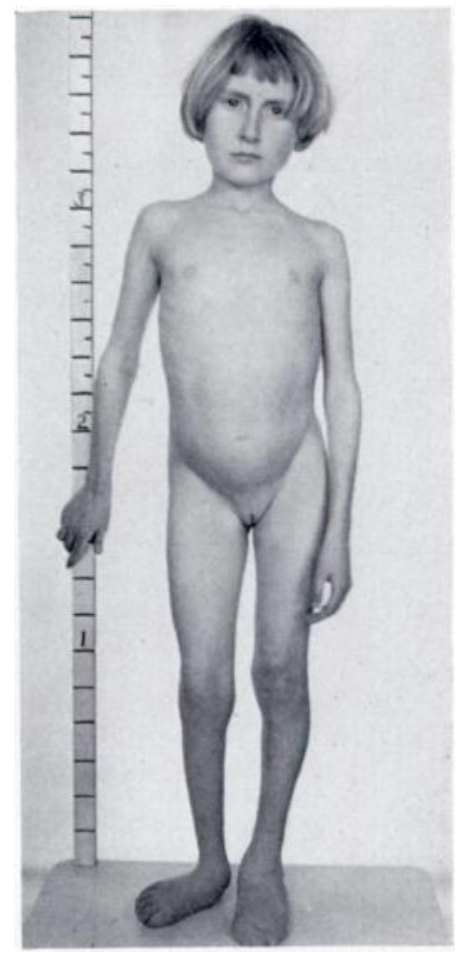

FIG. 4

Radiographic examination (November 1949) showed a soft-tissue mass in the pelvis and right side of the abdomen, with calcification in the right side of the pelvic cavity (Fig. 1). There was no lung or mediastinal lesion. Intravenous pyelography showed that the right kidney was high but probably normal. The left kidney was "full," with stasis in the left ureter. The bladder was deformed by an extrinsic mass lying mainly to its right side and above it. No abnormality was shown in the limbs.

Biopsy (December 1949)-A biopsy was performed by Mr W. A. Jackman. Through an incision parallel to the right iliac crest at the level of the third lumbar spinous process a hard grey lobulated mass was exposed. The tumour was adherent to the iliac crest and surrounding structures and extended anteriorly. A large piece was removed for examination.

The tumour was lobulated and on section showed a white cellular appearance with areas of haemorrhage. Microscopically it was composed of masses and cords of small cells with scanty cytoplasm and darkly staining round or oval nuclei. These cells had a tendency to be arranged around circular spaces containing radiating fibrils derived from the cellular cytoplasm - the classical rosettes of a neuroblastoma. The tumour was more highly differentiated than many neuroblastomata seen at this age, in that the rosettes were numerous, but there were no 
ganglion cells (Fig. 2). Treatment was thought unlikely to benefit the child, and she was allowed to go home.

Progress-She was next seen a year later when she was admitted in good general health apart from deformity of the feet (Fig. 3) and some urinary retention with overflow, and consequent cystitis. The mass was no longer clearly felt, and the abdomen much less distended; in fact the presence of any residual tumour was in doubt. There was no sign of metastases, visceral or skeletal. During the next eight and a half years the child was admitted on twelve occasions for treatment of the paralysis of the legs and the impaired bladder function, which led to progressive deterioration in kidney function (Figs. 4 to 6). The child eventually died in June 1959 from uraemia at the age of ten years. Only a limited necropsy was performed.

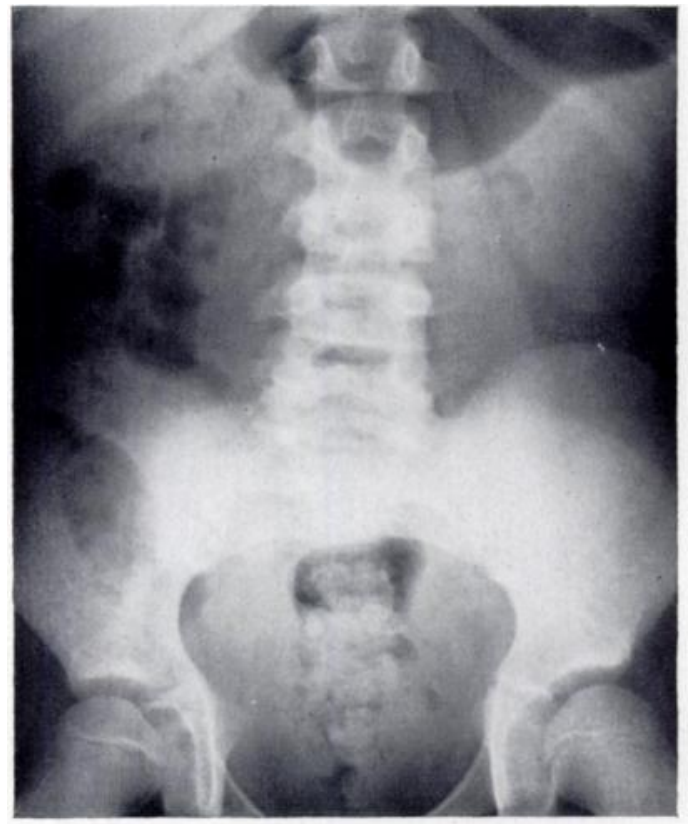

FIG. 5

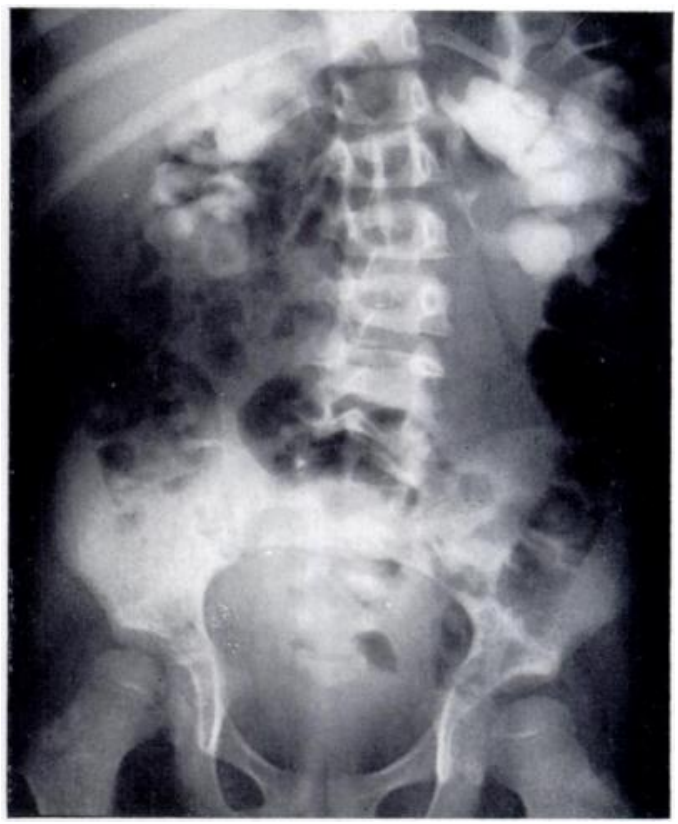

Fig. 6

Figure 5-Intravenous pyelogram (forty-five minutes) at the age of six and three-quarter years. Bilateral hydronephrosis; distended bladder. Note the calcification in the right side of the pelvis and the slight lumbar scoliosis. Figure 6-Aged eight years and nine months. Very little calcification persists in the pelvis.

Throughout the period of observation the radiographs showed slight lumbar scoliosis to the left and persisting imperfect outline of the right psoas, in marked contrast with the clear outline of the left psoas.

The abdomen showed no abnormality apart from gross pyonephrosis and dilation of the bladder and ureters. The lumbar spine and sacrum were removed for detailed examination. The chest and skull were not opened.

Pathology of the specimen-The specimen consisted of the whole lumbar spine with sacrum attached. The nerve roots were exposed opposite the lower four lumbar vertebrae by cutting away the laminae and the lateral masses. The spinal theca in the region of the third and fourth lumbar nerves was thickened, and on the right side there was a layer of tough fibrous tissue densely attached to the theca and extending out over both lumbar nerve roots. This material was not bulky and had not invaded the bone of the intervertebral canal. There was no similar tissue on the left side. The nerve roots on the left side appeared normal, as did the first and second lumbar roots on the right. The third and fourth roots, lying within their intervertebral foramina, were embedded in a mass of slightly brownish fibrous tissue. This was densely adherent to the bone but could be dissected away from it (Fig. 7). On coronal section through these two nerve roots the nerve trunks were seen running through shiny fibrous tissue. 
The anterior surface of the spinal theca was densely adherent to the posterior aspect of the bodies of the third, fourth and fifth lumbar vertebrae. The theca was normal as far as the level of the fourth and fifth lumbar vertebrae, where the cauda equina was embedded in rather dense fibrous adhesions which had a slightly brownish tint. These adhesions lay under an area where the theca was thickened. There was no sign of tumour within the thickened theca. The spinal cord above this level appeared normal macroscopically.

Microscopically, sections from many different levels in the dense fibrous tissue to the right of the lumbar spine showed no sign of tumour until the area just outside the intervertebral foramina was reached. Here, in a matrix of dense collagen, was a group of abnormal ganglion cells most of which were multinucleate but without mitoses (Figs. 8 and 9). There were no really primitive cells and consequently no rosettes. The appearance was that of a ganglioneuroma. The proportion of tumour to fibrous tissue was very low.

Microscopic examination of the lumbar spinal cord revealed an area of demyelination

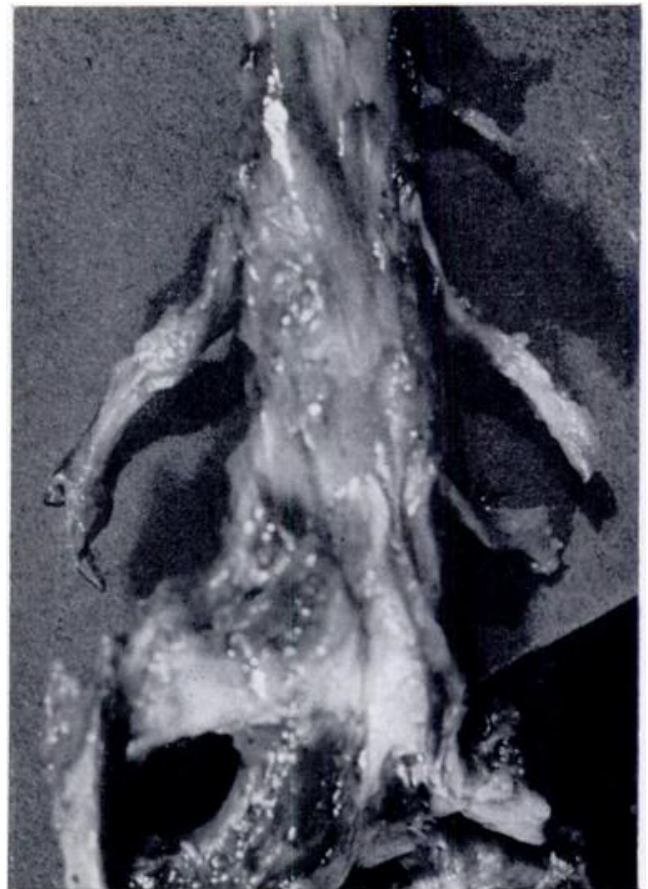

FIG. 7

Anterior view of lumbar spinal theca showing fibrous thickening of the third and fourth right lumbar nerve roots dissected out of their intervertebral foramina.

extending up the posterior columns on the right side. There was no invasion of the theca by tumour cells, and no fibrosis within the theca. The tissue in which calcification had been detected radiographically was not represented in the specimen, and the calcification had almost disappeared in the later radiographs (Fig. 6).

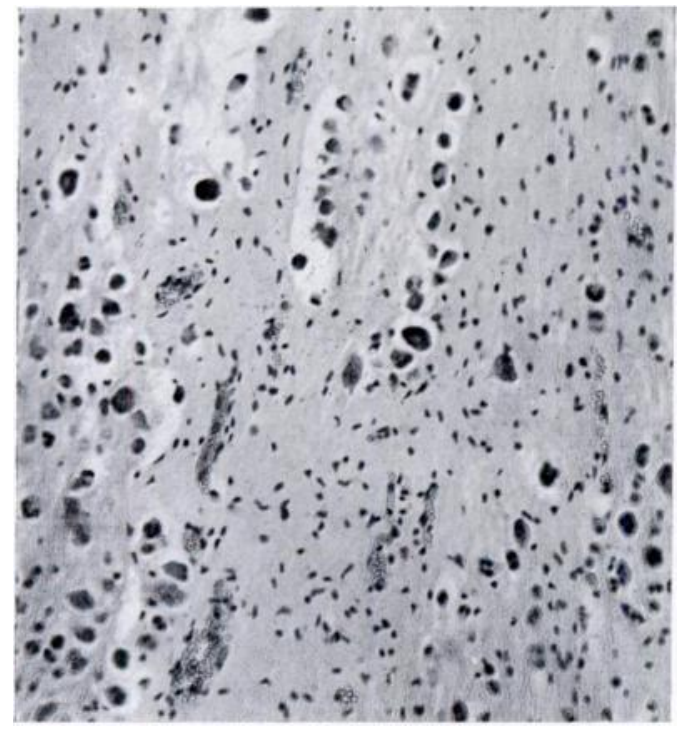

Fig. 8

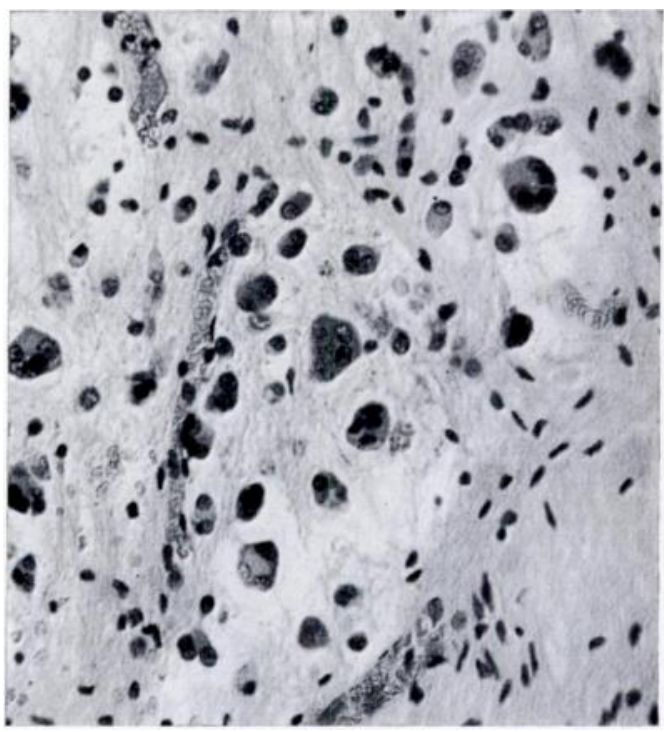

Fig. 9

Figure 8-Section of tissue outside right intervertebral foramina showing groups of ganglion cells. (Haematoxylin and eosin, $\times 150$.) Figure 9-Same section showing multinucleate ganglion cells. (Haematoxylin and eosin,

VOL. 44 B, NO. 4, NOVEMBER 1962 $\times 300$.) 


\section{DISCUSSION}

This child clearly had a neuroblastoma of the right side of the abdomen derived from the paravertebral sympathetic nerve tissue. The tumour disappeared spontaneously during the next eighteen months, subsequent treatment being directed entirely to the relief of the neurological lesions which persisted: anaesthesia of the left foot and lower part of the left leg with recurring sores, slight impairment of sensation in the right leg, paralysis of both legs below the knees, and a neurogenic bladder causing retention with overflow. The tibialis posterior was the only muscle below the knee which appeared to act sufficiently strongly to produce recurring equino-varus until transplanted through the intermuscular septum, after which it retained the foot in a position of calcaneo-valgus.

These neurological findings seemed clearly to indicate pressure within the lumbar or lumbo-sacral spinal canal from a dumb-bell tumour, and it was for this reason that this part of the spine was procured for careful study. The radiological appearance of calcification in the right side of the pelvis was presumably due to a change in a peripheral part of the tumour and this had almost disappeared in later years. The detailed study of the specimen gave histological confirmation that the neuroblastoma had matured to become a ganglioneuroma, of which very little tissue indeed persisted at death nine and a half years after the original tumour tissue was examined.

\section{SUMMARY}

A three-month-old girl presented with a massive abdominal tumour arising from the right lumbar region. Microscopic examination of a biopsy specimen showed a typical neuroblastoma. No treatment was given except that necessary symptomatically for paralysis caused by compression of the cauda equina. Spontaneous regression was accompanied by maturation to a small ganglioneuroma, found at necropsy examination at the age of ten years. Death was from urinary infection due to a persistent neurogenic bladder.

We wish to express our gratitude to Dr P. S. A. Heyworth of St Sampson's, Guernsey, who originally sent the child to Bristol and eventually performed the necropsy and provided us with the specimen for detailed examination, to Professor C. B. Perry, Mr W. A. Jackman and Mr Ashton Miller, all of whom took part in the treatment of the child, and to Dr J. H. Middlemiss who reviewed the large number of radiographs taken over the years.

\section{REFERENCES}

Phillips, R. (1953): Neuroblastoma. Annals of the Royal College of Surgeons of England, 12, 29.

Russell, D. S., and Rubinstern, L. J. (1959): The Pathology of Tumours of the Nervous System. London: Edward Arnold (Publishers) Ltd.

Willis, R. A. (1960): Pathology of Tumours. Third edition. London: Butterworth \& Co. (Publishers) Ltd. 